\section{Tetracycline treatment in a food-borne outbreak of toxoplasmosis}

Toxoplasmosis is common among all warm-blooded animals in most parts of the world. Food is a neglected source of infection but seems to have been responsible for the small outbreak described here.

\section{Case histories}

The three people concerned were men in their mid-twenties who shared a house in south London. The most severely affected man (case 1) developed a constant frontal headache eight days after moving into the house. The headache lasted a week, at the end of which time he noticed large, painful glands in the neck and groin. Eight days later he complained of severe malaise, intermittent low-grade fever and had generalised lymphadenopathy. Haematological investigation, chest $x$-ray examination, and Paul-Bunnell test results showed no abnormality. Six weeks after onset, however, a titre of $1 / 1024$ was obtained in the toxoplasma dye test and specific IgM titres were obtained by immunofluorescence (figure). A three-week course of oxytetracycline was started. Within a few days the patient felt well and the enlarged nodes gradually subsided over the following week. Four days after completing the antibiotic course severe symptoms and rapid enlargement of lymph nodes recurred. A month's treatment was then started with the standard, but potentially more toxic drugs, pyrimethamine and sulphadiazine.

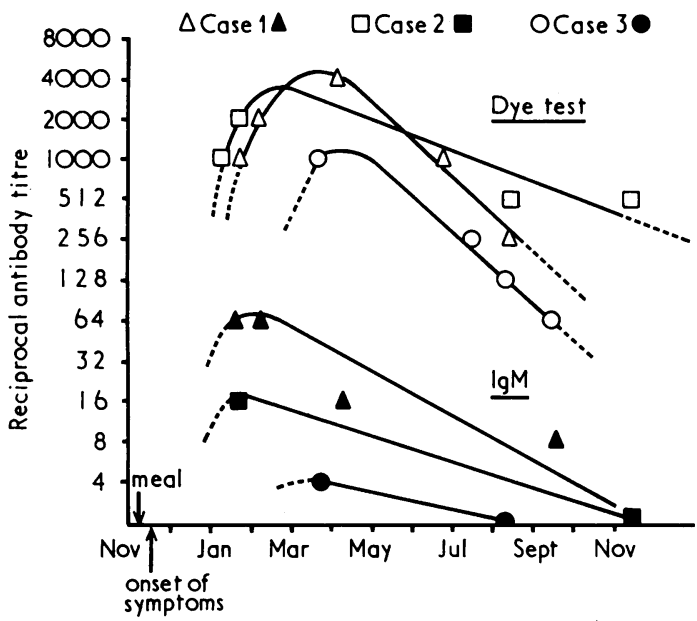

Changing titres of toxoplasma antibodies in three patients with food-borne toxoplasmosis.

This treatment gave no symptomatic relief, the glands remaining large and painful. Six months after its onset the disease was highly active and interfered with the patient's work. A final month's course of oxytetracycline and prednisolone was given. This time there was prolonged symptomatic relief interrupted only by two possible minor relapses.

The first patient's brother (case 2) developed severe frontal headache, malaise, and cervical lymphadenopathy at the same time and showed similar high, rising titres in the toxoplasma dye test. His symptoms were less severe at first, but over the next two months he developed increasing malaise. He was then started on a month's course of pyrimethamine and sulphadiazine, but showed no clinical improvement, and symptoms only gradually abated over the next few months.

Infection in the third person was essentially subclinical, apart from a severe week-long frontal headache occurring at the same time as his two friends. No enlarged glands were noted at any time.

\section{Comment}

Outbreaks of toxoplasmosis are rare. In one incident concerning an Irish family, ingestion of oocysts from the faeces of an infected cat was the likely source. ${ }^{1}$ In the present outbreak there was no direct contact with cats. The relevant communal meal taken included inadequately grilled lamb-a well-known source of infective cysts. ${ }^{2}$ Eight days later symptoms were first noticed, although four guests at the meal suffered no ill effects and, in two of them, dye-test titres several months later were less than 16 . A similar clustering of cases has been reported from the USA recently, in which five out of $\mathbf{4 0}$ medical students were infected, all of whom had eaten raw hamburgers from the same source. ${ }^{3}$

The lymphadenopathy in this form of toxoplasmosis is a host immune response, and the disease runs a relapsing course with eventual recovery. Thus treatment is difficult to assess. The poor results with pyrimethamine and sulphadiazine in cases 1 and 2 do, however, seem characteristic. ${ }^{4}$ Spiramycin has been recommended as an alternative in such difficult cases, but there is no convincing evidence of its clinical advantage. ${ }^{4}$ In view of the good clinical response to oxytetracycline in case 1 we suggest that an adequately long course of tetracycline should be considered, particularly in prolonged, debilitating forms of lymphadenopathic toxoplasmosis. Certainly experimental infections in animals have responded well to tetracyclines. ${ }^{5}$

We thank Dr D G Fleck of St George's Hospital, London, for his advice and for carrying out the serological tests.

${ }^{1}$ Fleck, D G, Chessum, B S, and Perkins, M, British Medical fournal, 1972, 3,111 .

2 Jacobs, L, Remington, J S, and Melton, M L, fournal of Parasitology, 1960, 46, 23.

${ }^{3}$ Kean, B H, Kimball, A C, and Christenson, W N, fournal of the American Medical Association, 1969, 208, 1002.

4 Beverley, J K A, British Medical fournal, 1973, 2, 475.

${ }^{5}$ Garin, J P, Perrin-Fayolle, M, and Paliard, P, Presse Médicale, 1965, 73, 531 .

(Accepted 20 fanuary 1977)

Department of Bacteriology, Westminster Medical School, London SW1

A FERTIG, $\mathrm{MB}, \mathrm{BCH}$, senior house officer in pathology

S SELWYN, MD, MRCPATH, reader in medical microbiology

St Stephen's Hospital, London SW10

M J K TIBBLE, MB, BS, medical registrar

\section{Oral contraceptives and benign liver tumours}

In 1973 Baum et al described seven women with benign hepatic tumours, all of whom had been using oral contraceptives. ${ }^{1}$ Since then well over 100 similar cases have been reported. Unfortunately, cancer registries are of no use as a data source for population studies of this problem since they are concerned only with malignant tumours. Accordingly, we decided to search several other readily accessible data bases for cases of benign liver tumour in women of childbearing age.

\section{Methods and results}

Royal College of General Practitioners oral contraception study ${ }^{2}$-In total, 216000 woman-years of observation have now accumulated in this investigation, of which 116000 relate to takers or ex-takers of oral contraceptives.

Not a single case of benign (or malignant) liver tumour has been identified.

Oxford/Family Planning Association follow-up study of women using different methods of contraception ${ }^{3}$ - In this study a total of 83000 womanyears of observation are now available for analysis, of which $40 \%$ relate to 
oral contraceptive users. Again, not a single case of liver tumour has been identified.

Oxford record linkage study $y^{4}$-This investigation covers hospital admissions and deaths occurring in a total population of over 1000000 . The files for the years 1970-5 were searched. No women of childbearing age were found who had had a benign liver tumour.

Scottish national diagnostic index $x^{5}$ - This system is concerned with hospital admissions and deaths occurring in a population of about five million. A search was made for cases of benign liver tumour occurring in women of childbearing age during the years 1968-74. None was found. Nevertheless, one of us (IBM) who was contacted during the course of this search recalled seeing a young woman with a benign liver tumour in 1972. Brief details are as follows: A 23-year-old woman had been on oral contraceptives for about two years when she underwent laparotomy for abdominal pain in July 1972. At operation a lesion $8 \cdot 6 \cdot 4 \mathrm{~cm}$ was found in the right lobe of the liver. No other abnormal findings were present, and the lesion was excised. Slides from the lesion were examined by several pathologists, who variously regarded it as a "hamartoma," "focal nodular hyperplasia," or a "hyperplastic nodule." There was, of course, some concern over why this case had been missed by the Scottish national diagnostic index. It was found that a records clerk had interpreted the word "hamartoma" (which was the original pathological

\section{Comment}

We have succeeded in identifying only one case of benign liver "tumour" in a woman of childbearing age, despite our extensive searches. Even allowing for the possibility that one or two further cases might have been missed by incomplete coverage or by coding errors, it seems clear that benign tumours of the liver are extremely rare in both users and non-users of oral contraceptives. Nevertheless, since some reports have indicated that the risk of liver tumours increases with the duration of use of oral contraceptives, it is clearly essential to remain on the alert.

${ }^{1}$ Baum, J K, et al, Lancet, 1973, 2, 926.

2 Royal College of General Practitioners, Oral Contraceptives and Health. London, Pitman Medical, 1974.

3 Vessey, M P, et al, fournal of Biosocial Science, 1976, 8, 373.

- Baldwin, J A, Proceedings of the Royal Society of London, (B), 1973, 184, 403.

${ }^{5}$ Heasman, M A, Health Bulletin, 1968, 26, 1.

(Accepted 20 fanuary 1977)

Department of Social and Community Medicine, Oxford

M P VESSEY, MD, FFCM, professor

Royal College of General Practitioners Oral Contraception Study, Manchester

C R KAY, MD, FRCGP, director

Unit of Clinical Epidemiology, Oxford

Information Services Division, Scottish Health Service Common Services Agency, Edinburgh

J A CLARKE, MB, CHB, community medicine specialist

Royal Infirmary, Edinburgh

I B MACLEOD, BSC, FRCSED, consultant surgeon diagnosis) as "haematoma" and coded the case as a closed injury of the liver.

J A BALDWIN, MD, FFCM, director

\section{Case report}

A $3 \frac{1}{2}$-year-old boy went to stay at his aunt's home with his parents. His mother had asked the aunt to ensure that the wide selection of tablets kep in the house should be placed in a position inaccessible to the boy, but these were merely put in a shoe box on a window sill. The tablets included paracetamol, quinine, phenylbutazone, aspirin, practolol, chloramphenicol, and various diuretics. The boy's aunt found him eating some of these tablets, but nothing was done until two hours later, when his mother noticed that he was unsteady on walking. In the emergency and accident department no abnormal signs were found and shortly after arrival he vomited a great deal spontaneously, including all his lunch. Screening of the urine showed quinine but no salicylate, barbiturate, tricyclics, paracetamol, benzodiazepine, or phenothiazine.

The next morning ( 15 hours later) he was drowsy but responded to command. Both pupils were dilated and did not react to light and he was completely blind. The fundi appeared normal. About 28 hours after ingestion of the tablets, bilateral stellate block was carried out by paratracheal approach using $5 \mathrm{ml}$ of $0.5 \%$ bupivacaine on the right and $5 \mathrm{ml}$ of $0.25 \%$ on the left Half an hour was allowed to elapse between blocking the first and second sides. About 30 minutes after the bilateral block he began moving his eyes in relation to a light and a face. Four and a half hours later a second bilateral stellate block was carried out. Twelve hours later central vision was normal but peripheral vision was poor.

Three days after ingestion of the tablets retinal oedema and blurring of the optic disc margins were present for the first time. A peripheral visual defect was still present. A month after admission both discs were pale and there was gross attenuation of the retinal vessels in each eye.

\section{Comment}

Quinine is rapidly absorbed from the gastrointestinal tract. This patient presented late and vomited a great deal shortly after he was first seen. Gastric lavage could have been performed at that time but recovery of an appreciable amount of the quinine was unlikely. Treatment by stellate ganglion block has been described in several reports but its effectiveness has usually been difficult to evaluate owing to the difficulty in comparing untreated patients with those who have received treatment. The definite change in visual function which occurred within minutes of stellate block in the cases described by Glick and Mumford, ${ }^{3}$ Bankes et $a l,{ }^{4}$ and in the present patient suggests that this treatment has an effect. Bilateral stellate blocks have been recommended for the treatment of various arrhythmias and, in particular, paroxysmal atrial tachycardia.

It is necessary to allow half an hour or more to elapse between performing the stellate block on the second side. This allows any complications of the procedure to be detected. These include pneumothorax, block of either the vagus or inferior laryngeal nerve (hoarseness was observed after performing the block on both occasions in this case), and brachial plexus block. The cardiac accelerator nerves may be paralysed, with the possibility of a resultant vagal cardiac arrest, and some authorities recommend that intravenous atropine should be given routinely if a bilateral stellate block is to be performed. ${ }^{5}$

The normal appearance of the fundi during the acute phase of this child's illness made it difficult to incriminate quinine initially. There is still controversy whether constriction of the arteries is the primary effect or whether narrowing of the arteries occurs secondary to toxic effects of quinine directly on the retina.

This patient is the youngest to be described who has received a stellate block, which was found to be a simple and innocuous procedure.

${ }^{1}$ British Medical fournal, 1976, 2, 861.

${ }^{2}$ Grant, W M, Toxicology of the Eye, p 870. Springfield, Thomas, 1974.

${ }^{3}$ Glick, L, and Mumford, J, British Medical fournal, 1955, 2, 94.

${ }^{4}$ Bankes, J L K, Hayward, J A, and Jones, M B S, British Medical fournal, diagnosis and the effect of stellate block in a very young child. $1972,4,85$

${ }^{5}$ Moore, D C, Regional Block, 4th edn, p 135. Springfield, Thomas, 1965.

(Accepted 1 February 1977)

The main preventive treatment for night cramp is still quinine sulphate. ${ }^{1}$ There is little objective evidence that this drug is effective but many case reports of partial or complete permanent blindness as a result of accidental or suicidal ingestion of quinine have been published.2 A further case is described to show the difficulties in

\section{Stellate block for quinine blindness in a child}

Northwick Park Hospital and Clinical Research Centre, Harrow, Middlesex HA1 3UJ

H B VALMAN, MD, MRCP, consultant paediatrician

D C WHITE, FFARCS, consultant anaesthetist 